Check for updates

Cite this: RSC Adv., 2018, 8, 24534

\title{
Selective yields of furfural and hydroxymethylfurfural from glucose in tetrahydrofuran over $\mathrm{H} \beta$ zeolite $\dagger$
}

\author{
Jin Tan, (D) abc Haiyong Wang, ${ }^{\text {abc }}$ Longlong Ma, ${ }^{\text {*abc }}$ Chenguang Wang, ${ }^{\text {abc }}$ \\ Qiying Liu, (D) abc Qi Zhang (D) ${ }^{\text {abc }}$ and Minghong $\mathrm{He}^{\mathrm{abc}}$
}

\begin{abstract}
Several simple and effective solvents combined with $\mathrm{H} \beta$ zeolite were tested to selectively convert glucose into furfural and hydroxymethylfurfural in this work. The physicochemical properties of typically different polar aprotic solvents were compared. Tetrahydrofuran was found to be a suitable solvent in the selective conversion of glucose. The effect of reaction parameters, such as temperature, reaction time, water content, glucose dosage and protonic acid addition, on the product distribution were investigated in detail. Furfural and hydroxymethylfurfural could be selectively produced in this system, and the highest yields of furfural and hydroxymethylfurfural were up to $35.2 \%$ and $49.7 \%$ respectively. Furfural could be stable in a tetrahydrofuran medium when adding $5 \mathrm{wt} \%$ water in the absence of extra protonic acid. However, furfural production was extremely suppressed after addition of an acidic inorganic salt, which increased the yield of hydroxymethylfurfural. This investigation indicates a simple and feasible method to selectively produce furfural and hydroxymethylfurfural from renewable cellulosic carbohydrates.
\end{abstract}

Received 13th May 2018

Accepted 25th June 2018

DOI: $10.1039 / \mathrm{c} 8 \mathrm{ra04060e}$

rsc.li/rsc-advances and levulinic acid (LA) over acid catalyst. ${ }^{6-8}$ Production of FFA from hexose is technologically challenging. However, some literatures have reported that lower yield of FFA can be formed from hexose during hydrothermal treatment in the absence of catalysts under extreme conditions (high temperature and high pressure). ${ }^{9-12}$ Furthermore, FFA can be also achieved with high selectivity in the catalytic fast pyrolysis of glucose by using ZK-5 zeolite via its small pore size. ${ }^{13}$ Until few years ago, Dumesic and his team found that FFA as well as other products are easy to be obtained from glucose under mild conditions over $\mathrm{H} \beta$ zeolite in $\gamma$-valerolactone (GVL)/water solvent and they present a viewpoint that the use of zeolite catalysts in lactone/water solvents offers new routes for the selective conversion of renewable biomass feedstocks. ${ }^{14}$ Then $\mathrm{H} \beta$ zeolite combined with $\gamma$-butyrolactone $(\mathrm{GBL}) /$ water are adopted to convert hexoses and other cellulosic carbohydrates (e.g., glucose, fructose, sucrose, cellulose) into FFA. ${ }^{15}$ In order to achieve FFA with higher yield from hexoses or cellulosic carbohydrates, the modified versions of $\mathrm{H} \beta$ zeolite (Fe, $\mathrm{Zn}$ and $\mathrm{Zr}$ metals are loaded on the $\mathrm{H} \beta$ zeolite via ion-exchanged route respectively) are tested to be efficient catalysts for FFA production in GVL. ${ }^{16}$

According to the possible mechanism of glucose to FFA, isomerization of glucose into fructose is an important step over Lewis acid site and the produced fructose is the substrate for the rearrangements and the retro-aldol condensations. ${ }^{15,17}$ Nowadays, the catalysts used in the isomerization are divided into enzyme, Lewis acid and base catalyst. The best catalyst for isomerization is enzyme. However, this process suffers from various drawbacks such as the need of low concentrated 
solutions of glucose with high purity and limited operating temperature range. ${ }^{18}$ As for base catalyst, monosaccharides are unstable under strong alkaline conditions and degrade into more than 50 different byproducts. ${ }^{19}$ Therefore, most work have been conducted on Lewis acid catalysts. Among the various Lewis acid catalysts, $\mathrm{H} \beta$ zeolite before and after dealuminizing procedure are tested to be an efficient catalyst for isomerization. ${ }^{20}$ Meanwhile, $\mathrm{H} \beta$ zeolite is compatible with the subsequent dehydration reaction for FFA and HMF production from glucose due to the physicochemical properties, which the enriched Lewis acid sites on the external surface are in favor of isomerization, and the strong Brønsted acid sites located in micropores are the active sites for hydrolysis reaction to FFA, HMF and LA formation. ${ }^{21}$

All of those investigations verify a fact that not only hemicellulose but also cellulose can be converted to FFA. However, it is obviously noticed that the mediums playing for FFA and HMF production from hexoses or cellulosic carbohydrates only depend upon the lactone/water. ${ }^{14-16,22-24}$ Despite the excellent properties of lactone (e.g., GVL, GBL) in biomass conversion, the large-scale and industrial synthesis of lactone is highly limited due to the reduction of commercially synthetic materials. ${ }^{25}$

Tetrahydrofuran (THF), a sustainable kind of polar aprotic solvent as well as lactone, is derived from renewable biomass directly. ${ }^{26}$ Moreover, it has a similar five-membered ring structure with that of lactone. It is deduced that the synergistic effect between $\mathrm{H} \beta$ zeolite and lactone enables the selective $\mathrm{C}-\mathrm{C}$ bond cleavage of hexoses into pentoses and promotes the subsequent dehydration of pentoses to FFA. ${ }^{14,15}$ In this work, THF medium combined with $\mathrm{H} \beta$ zeolite was performed to break through the limitation for solvent (lactone) application in the selective synthesis of FFA and HMF from hexoses or cellulosic carbohydrates. Thus, a cost-effective reaction system ( $\mathrm{H} \beta$ zeolite and THF) was employed and the influential mechanism on products distribution were investigated in detail. The reaction conditions of this system for the selective conversion of glucose to FFA and HMF were discussed.

\section{Experimental}

\section{Materials}

$\mathrm{H} \beta$ zeolite $(\mathrm{Si}: \mathrm{Al}=25)$ was provided by catalyst plant of Naikai University, China. Fructose (purity $>99.0 \%$ ) was purchased from MYM Biological Technology Company Limited; glucose and $\mathrm{KHSO}_{4}$ were all obtained from Damao Chemical Reagents Company, China. Tetrahydrofuran (THF), dimethyl sulfoxide (DMSO), sulfolane, dioxane and $N, N$-dimethylformamide (DMF) were bought from Guangdong Guanghua Sci-Tech., Co., Ltd., China. The standard compounds of FFA, HMF and LA were all purchased from Aladdin Reagent Company. All reagents were of analytical grade and used without further purification.

\section{Reaction procedure}

$\mathrm{H} \beta$ zeolite was put into a furnace and calcined at $823 \mathrm{~K}$ for 300 min. Then conversion of glucose into FFA and HMF was conducted in a $25 \mathrm{~mL}$ stainless steel reactor with a Teflon inner.
$0.5 \mathrm{~g}$ of glucose, $0.1 \mathrm{~g}$ of $\mathrm{H} \beta$ zeolite and $9.5 \mathrm{~g}$ of solvent were put into the reactor. In order to avoid oxidation, high purity nitrogen was used to remove air inside the reactor. After that, the reactor was heated to the expectant temperature and maintained for a certain period of time. The reaction was halted and the system was cooled down to room temperature by cold water when reaction was completed. The mixed liquid and catalyst was separated through a centrifuge at the rotational speed of $5000 \mathrm{rpm}$ for $5.0 \mathrm{~min}$. The programs for catalyst recycle were performed after $\mathrm{H} \beta$ zeolite was calcined again at $823 \mathrm{~K}$ for $300 \mathrm{~min}$.

\section{Analytic methods}

The qualitative analysis of glucose, fructose, FFA, HMF and LA were determined using HPLC (Waters 2695) equipped with a SH1011 column $(8.0 \times 300 \mathrm{~mm}, 6 \mathrm{~mm}$ particle size, Waters $)$ through an external standard method. The mobile phase was an aqueous solution of sulfuric acid ( $5 \mathrm{mM}$ ) at the flow rate of 0.5 $\mathrm{mL} \mathrm{min}^{-1}$ and the column was kept at $323 \mathrm{~K}$. A Waters 410 refractive index detector (operated at $318 \mathrm{~K}$ ) was adopted to detect glucose, fructose and LA, while a UV detector (with the wavelength of $284 \mathrm{~nm}$ ) was used to detect HMF and FFA. All liquid samples obtained after each experiments were diluted 20 times by deionized water before analysis. The relevant calculations for glucose conversion, mole yields of different products and carbon balance were in the following formulas:

$$
\begin{gathered}
\text { conversion }(\%)=\frac{n_{0}-n_{1}}{n_{0}} \times 100 \% \\
\text { mole yield }(\%)=\frac{n_{\mathrm{i}}}{n_{0}} \times 100 \% \\
\text { carbon balance }(\%)=\frac{\sum n_{\mathrm{c}_{\mathrm{i}}}}{6 n_{0}} \times 100 \%
\end{gathered}
$$

In the formula (1), $n_{0}$ and $n_{1}$ are the mole content of glucose before and after reaction. In the formula (2), $n_{0}$ represents the same meaning as in the formula (1), $n_{\mathrm{i}}$ was the mole content of each product (fructose, FFA, HMF, LA and formic acid) respectively. In the formula (3), $n_{\mathrm{c}_{\mathrm{i}}}$ is the total carbon mole content of each product (fructose, FFA, HMF, LA, formic acid and black char).

\section{Results and discussion}

\section{Production of FFA from glucose in various solvents}

In order to compare the properties of different solvents in the conversion of glucose into FFA, HMF and LA, several typically common solvents (e.g., THF, sulfolane, DMSO, dioxane and DMF) which have the same polar aprotic properties as lactone are selected as the reaction mediums. ${ }^{26-28}$ Table 1 shows the differences of five commonly used dipolar aprotic solvents in physicochemical properties. Lower boiling point (339 K) of THF indicates that it can be recycled easily when used as reaction solvent. ${ }^{26}$ 
Table 1 Physicochemical properties of five commonly used dipolar aprotic solvents ${ }^{29,30}$

\begin{tabular}{|c|c|c|c|c|c|}
\hline \multirow[b]{2}{*}{ Property } & \multicolumn{5}{|l|}{ Solvents } \\
\hline & Sulfolane & DMSO & DMF & THF & Dioxane \\
\hline Molecular weight & 120.2 & 78.1 & 73.1 & 72.1 & 88.1 \\
\hline Density $\left(\mathrm{g} \mathrm{cm}^{-3}\right)$ & 1.3 & 1.1 & 0.9 & 0.9 & 1.0 \\
\hline Boiling point $(\mathrm{K})$ & 560.3 & 462.1 & 426.1 & 339.0 & 374.0 \\
\hline Freezing point (K) & 301.4 & 291.6 & 212.6 & 165.0 & 284.8 \\
\hline Permittivity ( $\varepsilon u$ ) @298 K & $43.4^{a}$ & 46.7 & 36.7 & 7.6 & 2.2 \\
\hline Dipole moment (Debye) & 4.7 & 4.0 & 3.9 & 1.7 & 0.5 \\
\hline Viscosity (MPa s) @303 K & 10.4 & $2.0^{b}$ & $0.9^{c}$ & 0.6 & 1.1 \\
\hline Flash point (K) & 450.0 & 362.0 & 331.0 & 290.2 & 288.6 \\
\hline Autoignition point (K) & 801.0 & 575.0 & 718.0 & 594.1 & 353.0 \\
\hline
\end{tabular}

${ }^{a}$ Mean the temperatures at $303 \mathrm{~K} .{ }^{b}$ Mean the temperatures at $298 \mathrm{~K}$. ${ }^{c}$ Mean the temperatures at $293 \mathrm{~K}$.

Usually, the use of organic solvents in biomass conversion reactions can lead to high rates and improve selectivities through affecting the solubilities of substrate fractions and affecting chemical reaction thermodynamics. ${ }^{27,31}$ However, the yield and selectivity of FFA from hexoses and various cellulosic carbohydrates are significantly affected by the synergistic effects of zeolite and solvent. ${ }^{15}$ In this investigation, it is clearly seen from Fig. 1 that the highest total yield of FFA, HMF and LA was achieved at $49.4 \%$ in $\mathrm{THF}$, followed by dioxane $(43.8 \%)$. Although glucose has a high conversion in those solvents, the yields of FFA in sulfolane and DMSO are low, especially in DMF (because of the heavy char formation).

The selectivities of FFA, HMF and LA in various solutions show that FFA has the highest selectivity in THF, sulfolane and dioxane, and DMSO medium is in favor of HMF production (Fig. $\mathrm{S} 1 \dagger$ ). Different products selectivities are detected in various mediums by altering the extents of solvation of the initial and transition states of these catalytic processes. ${ }^{31}$ Moreover, solvent with different properties have different ability to transfer the hydrogen ions, which changes dispersion of hydrogen ions in solvent and further affect their catalytic behaviors. ${ }^{32}$ Generally, the polar phase is used to dissolve and convert sugars while the

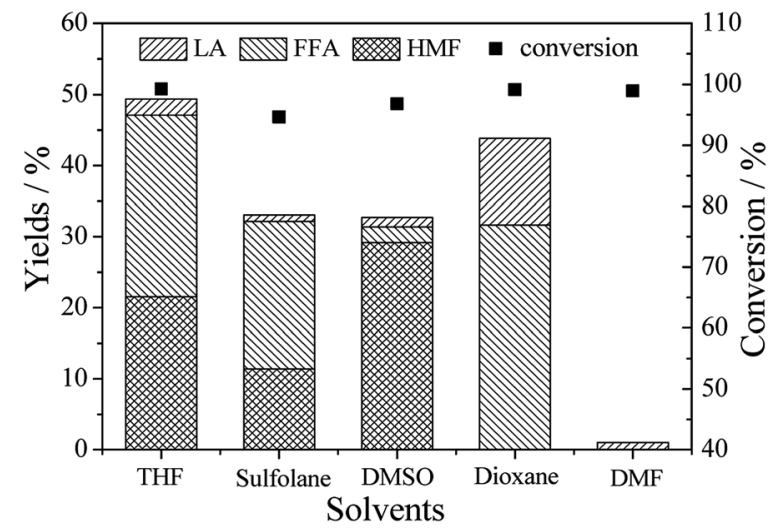

Fig. 1 Yields of FFA and other products in different solvents over $H \beta$ zeolite. Reaction conditions: $0.5 \mathrm{~g}$ glucose, $0.1 \mathrm{~g} \mathrm{H} \beta$ zeolite, $9.5 \mathrm{~g}$ solvent, $453 \mathrm{~K}, 120 \mathrm{~min}$. less polar phase is used to protect them (sugars, FFA, HMF and LA) from further exposure to the acidic catalyst in the polar phase. $^{33}$

$\mathrm{H} \beta$ zeolite in an aprotic organic solvent affects the reaction kinetics by changing the stabilization of the acidic proton relative to the protonated transition state. ${ }^{28}$ According to the physicochemical properties in Table 1 , it is easy to note that THF and dioxane have smaller dipole moments, which show weaker polarity of THF and dioxane compared with that of the other solvents. The reactivity of $\mathrm{H} \beta$ zeolite in the solvent is similar to that of a strong homogeneous Brønsted acid, which depends upon the extent of proton solvation relative to the polarity of solvent. ${ }^{28}$

Consequently, the generated furans (HMF and FFA) are prone to degradation/polymerization in the strong polar solvents. ${ }^{34,35}$ For example, they are ineluctable to repolymerization with hexoses and other chemicals to humins through aldol reaction and self-condensation over acid catalysts. ${ }^{36}$ In addition, these solvents give different products distribution, possibly due to the different synergistic effects between $\mathrm{H} \beta$ zeolite and aprotic organic solvents. ${ }^{24}$

\section{Effect of the temperature on products distribution}

Fig. 2 shows the versatile products distribution with increasing reaction temperature from $413 \mathrm{~K}$ to $493 \mathrm{~K}$. Fructose, FFA, HMF and LA were identified as the main products when glucose was used as substrate (Fig. S2 $\dagger$ ). As the reaction proceeded, a significant effect of reaction temperature on the yield of different products has been observed. Obviously, only 5.3\% yield of fructose was detected as the main product at $413 \mathrm{~K}$ accompanied by a few FFA and HMF. However, the highest total yield of FFA, HMF and LA was obtained at $56.2 \%$ with an increase in the reaction temperature at $453 \mathrm{~K}$. Meanwhile, there was nearly no fructose appeared in this mixture (the yield of fructose was only about $0.5 \%$ ). According to the possibly proposed pathway of FFA and HMF production from glucose, fructose is a key intermediate product through isomerization over Lewis acid, which is ready for the next rearrangements and retro-aldol condensations to FFA production. ${ }^{11,17}$ The enriched

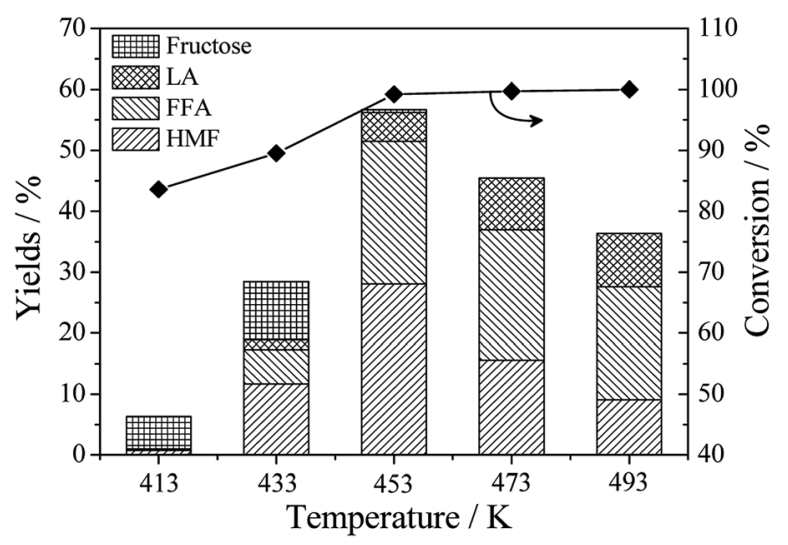

Fig. 2 Effect of the different temperature on products distribution. Reaction conditions: $0.5 \mathrm{~g}$ of glucose, $0.1 \mathrm{~g}$ of H $\beta$ zeolite, $9.0 \mathrm{~g}$ of THF, $0.5 \mathrm{~g}$ of water, $120 \mathrm{~min}$. 
Lewis acid sites on the external surface of $\mathrm{H} \beta$ zeolite are in favor of isomerization, while the strong Brønsted acid sites located in micropores are the active sites for hydrolysis reaction to HMF and LA formation. ${ }^{21}$ Herein, both bifunctional acid active sites resulted in the FFA, HMF and LA coproduction under this circumstances. Although higher temperature could accelerate the rate of chemical reaction, the unwanted side reactions also appeared at the same time. Moreover, these side reactions are much more thermally sensitive than other beneficial reactions for FFA, HMF and LA production, ${ }^{37}$ which results in the sharp decline of total yields at higher temperature.

\section{Effect of the water content on products distribution}

Water is not only a solvent in this system, but also a product of the dehydration procedure, involved in each step from glucose to FFA, HMF and LA. ${ }^{35}$ Previous investigation demonstrates that FFA and HMF yields and selectivity are significantly affected by solvent and cosolvent. ${ }^{38}$ In this work, the influence of the water percentage on products distribution was investigated and the results are showed in Fig. 3. Commonly, addition of organic solvent allows to suppress the activity of external acid sites of $\mathrm{H} \beta$ zeolite in the side reactions with increase in the selectivity to HMF and LA at high glucose conversion. ${ }^{39}$

Since glucose does not dissolve in the absolute organic solution, it is first converted to organic-soluble oligomers which could be reverted to glucose if diluted in water at mild conditions. ${ }^{40}$ Therefore, newly isomerized fructose were converted to FFA, HMF and LA rapidly with parallel reactions in the pure THF medium. Consequently, the final products mainly consisted of FFA, HMF and LA, and the total yield was achieved at $49.4 \%$. More and more fructose were detected with the increase of water percentage from $0 \mathrm{wt} \%$ to $40 \mathrm{wt} \%$. On the contrary, the total yield of FFA, HMF and LA declined to $24.9 \%$.

Previous investigation reveals that the interaction between solvents and acidic catalysts is affected obviously by the polarities of solution, determining availability of the acidic sites on the surfaces of the catalysts. ${ }^{35}$ Furthermore, the degradation of FFA is found to be suppressed drastically by the shielding effect of solvent. ${ }^{34}$ With increasing the content of water in THF, the

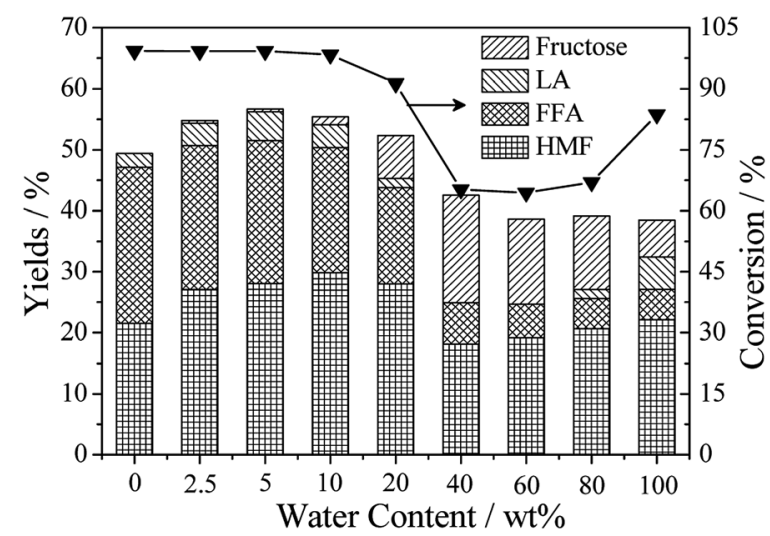

Fig. 3 Effect of the different water content on products distribution. Reaction conditions: $0.5 \mathrm{~g}$ of glucose, $0.1 \mathrm{~g}$ of $\mathrm{H} \beta$ zeolite, $9.5 \mathrm{~g}$ of solvent, $453 \mathrm{~K}, 120 \mathrm{~min}$. rehydration of HMF to LA and formic acid could be enhanced. ${ }^{41}$ Meanwhile, the undesired side reactions, such as polymerization between sugars, FFA, HMF, and LA, are also accelerated due to the enhanced polarity of solution. Based on these reasons, the yields of FFA, HMF and LA were achieved at 5.0\%, $22.1 \%$ and $5.3 \%$ in the absolute water respectively. The sharply changed conversion of glucose was attributed to the undesired coke formation in water medium. ${ }^{42}$

\section{Effect of the prolonged time on products distribution}

A typical time profile for the products distribution was performed and the results are exhibited clearly in Fig. 4. The changed yield curves of fructose, FFA, HMF and LA suggests a close relationship between relevant intermediate chemicals when glucose is converted in THF/water solution over $\mathrm{H} \beta$ zeolite. Obviously, fructose was the main product in a short period of time ( $9 \mathrm{~min})$, and it reduced gradually as time was prolonged to $360 \mathrm{~min}$. Usually, LA comes from the rehydration of HMF following fructose dehydration over acid catalysts. ${ }^{43-45}$ Consequently, a decrease of fructose results in the increase of HMF and LA at a certain period of time. The highest yield of HMF was obtained at $31.9 \%$ when reaction time was prolonged to $360 \mathrm{~min}$.

It is interesting to note that the yield of FFA reached the maximum value only at the time of $120 \mathrm{~min}$ as well as a high conversion of glucose. Stable yield of FFA was at about $24.4 \%$ no matter reaction time was further prolonged to $420 \mathrm{~min}$. This result indicates a fact that the degradation of FFA is suppressed drastically by THF. All of these results show a parallel reaction routes for glucose conversion: ${ }^{11,17}$ (i) isomerization of glucose into fructose and successive dehydration to HMF and LA. (ii) Conversion of the isomerized fructose into FFA through rearrangements and retro-aldol condensations.

\section{Effect of the glucose dosage on products distribution}

According to previous literatures, glucose isomerization, fructose diffusion and retro-aldol condensations are the three essential steps for FFA and HMF production. ${ }^{11,15,17}$ Initial substrates with high concentration can accelerate their diffused

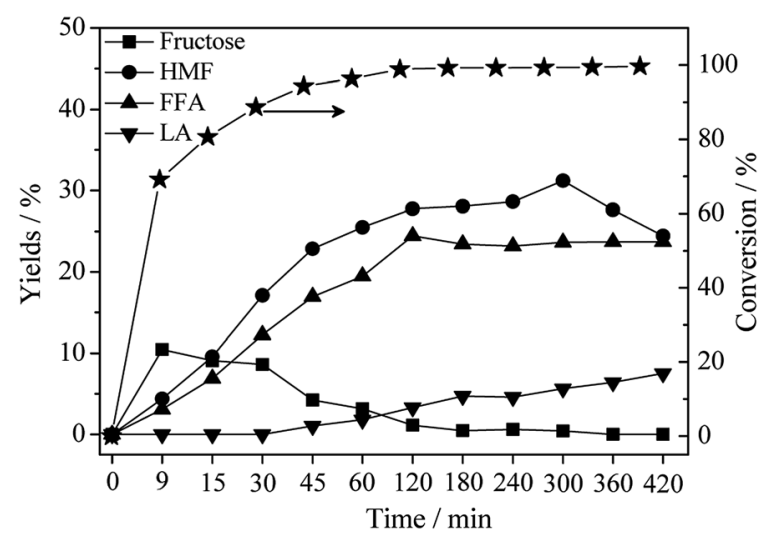

Fig. 4 Effect of the different reaction time on products distribution. Reaction conditions: $0.5 \mathrm{~g}$ of glucose, $0.1 \mathrm{~g}$ of H $\beta$ zeolite, $9.5 \mathrm{~g}$ of THF, $0.5 \mathrm{~g}$ of water, $453 \mathrm{~K}$. 
Table 2 Effect of the glucose dosage on products distribution ${ }^{a}$

\begin{tabular}{|c|c|c|c|c|c|c|c|c|c|c|}
\hline \multirow[b]{2}{*}{ Entry } & \multirow[b]{2}{*}{$\begin{array}{l}\text { Glucose } \\
\text { dosage/wt } \%\end{array}$} & \multirow[b]{2}{*}{ Conversion/\% } & \multicolumn{7}{|c|}{ Yields/\% } & \multirow[b]{2}{*}{ Carbon balance $/ \%$} \\
\hline & & & FFA & HMF & LA & Formic acid & Glucose & Fructose & $\begin{array}{l}\text { Black char } \\
\text { (C mol) }\end{array}$ & \\
\hline 1 & 0.1 & 100 & 31.9 & 15.4 & - & - & - & - & 1.2 & 43.9 \\
\hline 2 & 0.3 & 100 & 33.3 & 15.4 & 3.8 & 4.2 & - & - & 6.7 & 56.8 \\
\hline 3 & 0.5 & 100 & 33.9 & 19.4 & 4.5 & 4.3 & - & - & 8.5 & 63.8 \\
\hline 6 & 3.0 & 99.5 & 32.6 & 30.4 & 4.0 & 3.7 & 0.5 & - & 19.6 & 81.7 \\
\hline 7 & 4.0 & 99.5 & 31.1 & 28.0 & 3.5 & 3.9 & 0.5 & - & 22.4 & 80.5 \\
\hline 8 & 5.0 & 99.2 & 25.9 & 23.3 & 1.7 & 2.4 & 0.8 & 0.5 & 23.6 & 71.1 \\
\hline 9 & 6.0 & 97.3 & 20.7 & 22.3 & 1.4 & 1.9 & 2.7 & 1.4 & 25.1 & 70.2 \\
\hline 10 & 8.0 & 96.6 & 15.4 & 20.4 & 1.4 & 1.8 & 3.4 & 2.5 & 30.6 & 71.1 \\
\hline
\end{tabular}

rate into zeolite pores, which increases the risk for byproducts formation. ${ }^{46}$ Therefore, the yields of FFA, HMF and versus the glucose dosage were investigated and the results are exhibited in Table 2. Obviously, higher yields ( $>30 \%)$ of FFA were obtained when glucose dosage was lower than $4.0 \%$. However, it decreased to $15.4 \%$ sharply when $8.0 \mathrm{wt} \%$ glucose was used. The yield of HMF showed the same changes as FFA and the highest yield was achieved at $30.4 \%$ when glucose dosage was $3.0 \mathrm{wt} \%$. These declines are attribute to the covered carbon deposition on the Lewis and Brønsted acid sites of $\mathrm{H} \beta$ zeolite. ${ }^{15}$

The characterization of $\mathrm{H} \beta$ zeolite before and after reaction supported this viewpoint. The results of XRD patterns of $\mathrm{H} \beta$ zeolite before and after reaction show that catalyst almost remained integrity crystal structure (Fig. S3†). While carbon deposition was found on the surface external and internal surface (Fig. S4 $\dagger$ ), which resulted in the decrease of BET surface area and pore size (Table S1 $\dagger$ ). Moreover, these undesired carbon deposition covered the Lewis and Brønsted acid sites on the surface of $\mathrm{H} \beta$ zeolite, and decreased the effective active sites for FFA and HMF production (Fig. S5 and Table S2 $\dagger$ ) (Fig. 5).

Hence, the $\mathrm{H} \beta$ zeolite after one recycling run was calcined at $823 \mathrm{~K}$ for $300 \mathrm{~min}$ and used for the next run (Fig. 4). The activity of $\mathrm{H} \beta$ zeolite for FFA, HMF and LA production show a slight

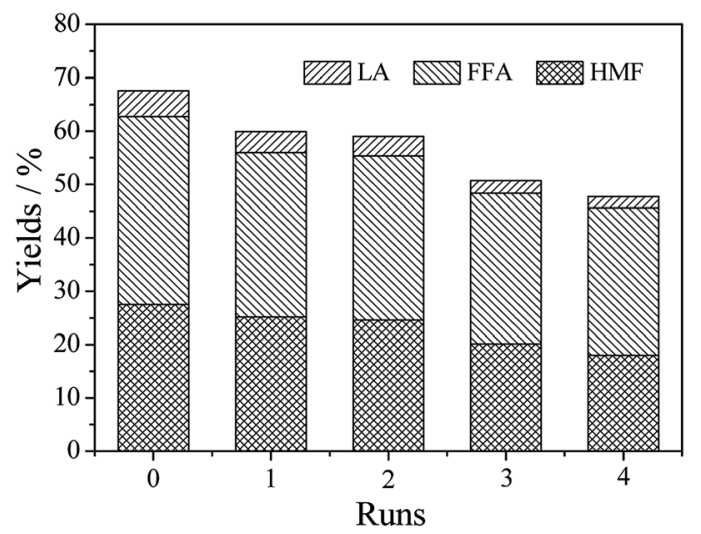

Fig. 5 Recycle of $\mathrm{H} \beta$ zeolite. Reaction conditions: $0.2 \mathrm{~g}$ of glucose, $0.1 \mathrm{~g}$ of $\mathrm{H} \beta$ zeolite, $9.5 \mathrm{~g}$ of THF, $0.5 \mathrm{~g}$ of water, $453 \mathrm{~K}, 120 \mathrm{~min}$. decrease after four recycling runs. For example, the total yield of FFA, HMF and LA was $67.5 \%$ over fresh $\mathrm{H} \beta$ zeolite, while it decreased to $47.7 \%$ after $\mathrm{H} \beta$ zeolite was calcined 4 times. With increasing the recycle times, the specific surface area and the acid centers of $\mathrm{H} \beta$ zeolite were decreased in the THF/water medium under those conditions. ${ }^{21}$

\section{Selective production of HMF from glucose}

Usually, the ability to form Brønsted acid sites for $\mathrm{H} \beta$ zeolite and other catalysts are relative to the polarity of solvent, which is a key factor for FFA and HMF production..$^{28}$ It is well known that lone electron pairs and no acidic hydrogen centers are two obvious features of polar aprotic solvent. ${ }^{27}$ Therefore, stable yield of FFA was detected in the mixture of various compounds under an extent of protonic acid. Additional $\mathrm{H}^{+}\left(\mathrm{KHSO}_{4}\right)$ was introduced into this reaction system to test the effect of protonic acid on FFA and HMF production and the results are listed in Table 3. An increase of $\mathrm{H}^{+}$was in favor of HMF and LA production, which sharply restrained the yield of FFA. $35.2 \%$ yield of FFA was obtained without adding $\mathrm{H}^{+}$, but the yield of FFA was only $5.9 \%$ after the extra $\mathrm{H}^{+}(0.2 \mathrm{mmol})$ addition. On the contrary, the yield of HMF increased from $27.5 \%$ to $49.7 \%$ as extra $\mathrm{H}^{+}$dosage increased from $0 \mathrm{mmol}$ to $1.2 \mathrm{mmol}$ gradually. Commonly, $\mathrm{KHSO}_{4}$ presents as solid in THF solvent with no water addition due to its poor solubility. The aqueous solution in this reaction system can be saturated by adding enough $\mathrm{KHSO}_{4}$, resulting in the separation of THF and water by saltingout effect and the formation of microemulsion system automatically. ${ }^{8}$ This newly produced microemulsion system is in favour of glucose dehydration in aqueous phase over protonic acid and HMF shift into THF, which results in the HMF increase (Fig. 6). ${ }^{6-8}$

According to the previous literature and the results of this work, the configuration transformation of monosaccharides, including ring opening, isomerization, ring closing, are the significant intermediate steps for FFA, HMF and LA production from glucose. ${ }^{11,15,17}$ The changed content of fructose in a short period of time indicated that it is a transitional product during glucose conversion in THF/water solution over $\mathrm{H} \beta$ zeolite. 
Table 3 Products distribution after adding different content of $\mathrm{H}^{+a}$

\begin{tabular}{|c|c|c|c|c|c|c|c|c|c|}
\hline \multirow[b]{2}{*}{ Entry } & \multirow[b]{2}{*}{$\begin{array}{l}\mathrm{H}^{+} \text {dosage/ } \\
\text { mmol }\end{array}$} & \multirow[b]{2}{*}{ Conversion/\% } & \multicolumn{6}{|c|}{ Yields/\% } & \multirow[b]{2}{*}{ Carbon balance $/ \%$} \\
\hline & & & FFA & HMF & LA & Formic acid & Glucose & $\begin{array}{l}\text { Black char } \\
\text { (C mol) }\end{array}$ & \\
\hline 1 & 0 & 100 & 35.2 & 27.5 & 4.8 & 5.3 & - & 18.9 & 80.5 \\
\hline 2 & 0.2 & 82.5 & 5.9 & 29.2 & 2.7 & 1.2 & 17.5 & 23.6 & 77.6 \\
\hline 3 & 0.3 & 90.1 & 5.8 & 35.3 & 3.5 & 4.0 & 9.9 & 24.3 & 77.8 \\
\hline 4 & 0.6 & 92.0 & 5.8 & 41.7 & 3.9 & 4.8 & 8.0 & 24.9 & 83.4 \\
\hline 5 & 0.9 & 97.0 & 5.8 & 45.2 & 5.0 & 6.5 & 3.0 & 25.2 & 83.4 \\
\hline 6 & 1.2 & 98.8 & 5.1 & 49.7 & 5.6 & 6.1 & 1.2 & 25.9 & 86.6 \\
\hline
\end{tabular}

${ }^{a}$ Reaction conditions: $0.2 \mathrm{~g}$ of glucose, $0.1 \mathrm{~g}$ of $\mathrm{H} \beta$ zeolite, $9.5 \mathrm{~g}$ of THF, $0.5 \mathrm{~g}$ of water, $453 \mathrm{~K}, 120 \mathrm{~min}$.

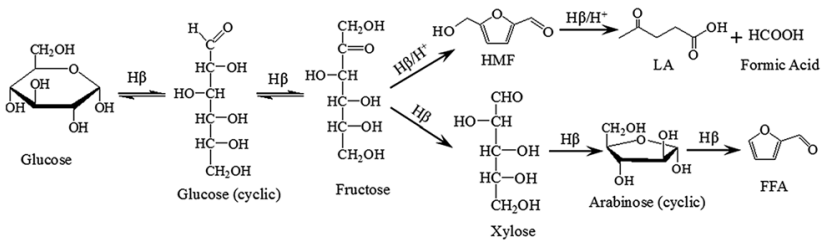

Fig. 6 Possible pathways of glucose conversion over $\mathrm{H} \beta$ zeolite and protonic acid.

Meanwhile, trace of arabinose was detected and it dehydrated to FFA easily through Brønsted acid. Two parallel pathways based on the produced fructose proceed simultaneously. While the extra protonic acid dosage in the solution decides the selectivities of FFA, HMF and LA production.

\section{Conclusions}

THF combined with $\mathrm{H} \beta$ zeolite were tested to be a simple and feasible system in the selective conversion of glucose into FFA and HMF. FFA could be efficiently produced with the highest yield of $35.2 \%$ when $2.0 \mathrm{wt} \%$ glucose dosage was used at $453 \mathrm{~K}$ for $120 \mathrm{~min}$ in THF medium by adding $5 \mathrm{wt} \%$ water. Yield of HMF could be enhanced through adding suitable $\mathrm{KHSO}_{4}$, which results in the extreme suppression for FFA production. FFA and HMF could be highly selective produced from glucose in this effective system by acidic inorganic salts.

\section{Conflicts of interest}

There are no conflicts to declare.

\section{Acknowledgements}

This work was supported by the National Natural Science Foundation of China (No. 51536009), Local Innovative and Research Teams Project of Guangdong Pearl River Talents Program (No. 2017BT01N092) and the Natural Science Foundation of Guangdong Province (2017A030308010).

\section{References}

1 J. B. Binder and R. T. Raines, J. Am. Chem. Soc., 2009, 131, 1979-1985.

2 F. López, M. T. García, M. J. Feria, J. C. García, C. M. de Diego, M. A. M. Zamudio and M. J. Díaz, Chem. Eng. J., 2014, 240, 195-201.

3 R. Sahu and P. L. Dhepe, ChemSusChem, 2012, 5(4), 751-761. 4 L. Bu, Y. Tang, Y. Gao, H. Jian and J. Jiang, Chem. Eng. J., 2011, 175, 176-184.

5 C. Chang, G. Xu, W. Zhu, J. Bai and S. Fang, Fuel, 2015, 140, 365-370.

6 P. Neves, S. Lima, M. Pillinger, S. M. Rocha, J. Rocha and A. A. Valente, Catal. Today, 2013, 218-219, 76-84.

7 E. Christensen, A. Williams, S. Paul, S. Burton and R. L. McCormick, Energy Fuels, 2011, 25, 5422-5428.

8 N. Shi, Q. Liu, Q. Zhang, T. Wang and L. Ma, Green Chem., 2013, 15, 1967-1974.

9 M. Sasaki, Z. Fang, Y. Fukushima, T. Adschiri and K. Arai, Ind. Eng. Chem. Res., 2000, 39, 2883-2890.

10 F. Jin and H. Enomoto, Energy Environ. Sci., 2011, 4, 382-397. 11 T. M. Aida, Y. Sato, M. Watanabe, K. Tajima, T. Nonaka, H. Hattori and K. Arai, J. Supercrit. Fluids, 2007, 40, 381-388.

12 B. M. Kabyemela, T. Adschiri, R. M. Malaluan and K. Arai, Ind. Eng. Chem. Res., 1999, 38, 2888-2895.

13 J. Jae, G. A. Tompsett, A. J. Foster, K. D. Hammond, S. M. Auerbach, R. F. Lobo and G. W. Huber, J. Catal., 2011, 279, 257-268.

14 E. I. Gürbüz, J. M. R. Gallo, D. M. Alonso, S. G. Wettstein, W. Y. Lim and J. A. Dumesic, Angew. Chem., Int. Ed., 2013, 52, 1270-1274.

15 J. Cui, J. Tan, T. Deng, X. Cui, Y. Zhu and Y. Li, Green Chem., 2016, 18, 1619-1624.

16 L. Zhang, G. Xi, Z. Chen, D. Jiang, H. Yu and X. Wang, Chem. Eng. J., 2017, 307, 868-876.

17 Z. Srokol, A. G. Bouche, A. van Estrik, R. C. J. Strik, T. Maschmeyer and J. A. Peters, Carbohydr. Res., 2004, 339, 1717-1726.

18 S. Despax, B. Estrine, N. Hoffmann, J. L. Bras, S. Marinkovic and J. Muzart, Catal. Commun., 2013, 39, 35-38. 
19 C. Liu, J. M. Carraher, J. L. Swedberg, C. R. Herndon, C. N. Fleitman and J. P. Tessonnier, ACS Catal., 2014, 4, 4295-4298.

20 J. Dijkmans, D. Gabriëls, M. Dusselier, F. de Clippel, P. Vanelderen, K. Houthoofd, A. Malfliet, Y. Pontikes and B. F. Sels, Green Chem., 2013, 15, 2777-2785.

21 L. Zhou, Z. Liu, Y. Bai, T. Lu, X. Yang and J. Xu, J. Energy Chem., 2016, 25, 141-145.

22 W. Li, Y. Zhu, Y. Lu, Q. Liu, S. Guan, H. Chang, H. Jameel and L. Ma, Bioresour. Technol., 2017, 245, 258-265.

23 T. Zhang, W. Li, Z. Xu, Q. Liu, Q. Ma, M. Jameel, H. Chang and L. Ma, Bioresour. Technol., 2016, 209, 108-114.

24 L. Zhang, G. Xi, K. Yu, H. Yu and X. Wang, Ind. Crops Prod., 2017, 98, 68-75.

25 Z. Zhang, ChemSusChem, 2016, 9, 156-171.

26 F. Cao, T. J. Schwartz, D. J. McClelland, S. H. Krishna, J. A. Dumesic and G. W. Huber, Energy Environ. Sci., 2015, 8, 1808-1815.

27 L. Shuai and J. Luterbacher, ChemSusChem, 2016, 9, 133155.

28 M. A. Mellmer, C. Sener, J. M. R. Gallo, J. S. Luterbacher, D. M. Alonso and J. A. Dumesic, Angew. Chem., Int. Ed., 2014, 53, 11872-11875.

29 U. Tilstam, Org. Process Res. Dev., 2012, 16, 1273-1278.

30 N. L. Cheng, Solvents handbook. Chemical Industry Press, Beijing, China, 3rd edn, 2002.

31 M. A. Mellmer, C. Sanpitakseree, B. Demir, P. Bai, K. Ma, M. Neurock and J. A. Dumesic, Nat. Catal., 2018, 1, 199-207.
32 X. Hu, S. Wang, R. J. M. Westerhof, L. Wu, Y. Song, D. Dong and C. Z. Li, Fuel, 2015, 141, 56-63.

33 J. Zhang, J. Zhuang, L. Lin, S. Liu and Z. Zhang, Biomass Bioenergy, 2012, 39, 73-77.

34 R. Karinen, K. Vilonen and M. Niemela, ChemSusChem, 2011, 4, 1002-1016.

$35 \mathrm{X} . \mathrm{Hu}, \mathrm{R}$. Westerhof, D. Dong, L. Wu and C. Z. Li, ACS Sustainable Chem. Eng., 2014, 2, 2562-2575.

36 S. J. Dee and A. T. Bell, ChemSusChem, 2011, 4, 1166-1173.

37 M. Daroch, S. Geng and G. Wang, Appl. Energy, 2013, 102, 1371-1381.

38 S. Peleteiro, A. M. da Costa Lopes, G. Garrote, R. BogelŁukasik and J. C. Parajó, Ind. Crops Prod., 2015, 77, 163-166. 39 V. V. Ordomsky, J. van der Schaaf, J. C. Schouten and T. A. Nijhuis, J. Catal., 2012, 287, 68-75.

40 J. Heltzel and C. R. F. Lund, Catal. Today, 2016, 269, 88-92. 41 A. Corma, S. Iborra and A. Velty, Chem. Rev., 2007, 107, 24112502.

42 I. van Zandvoort, Y. Wang, C. B. Rasrendra, E. R. H. van Eck, P. C. A. Bruijnincx, H. J. Heeres and B. M. Weckhuysen, ChemSusChem, 2013, 6, 1745-1758.

43 J. Tan, Q. Liu, L. Chen, T. Wang, L. Ma and G. Chen, J. Energy Chem., 2017, 26, 115-120.

44 W. Zhao, Y. Li, C. Song, S. Liu, X. Li and J. Long, Appl. Energy, 2017, 204, 1094-1100.

45 F. Yang, J. Fu, J. Mo and X. Lu, Fuel, 2013, 27, 6973-6978.

46 P. A. Son, S. Nishimura and K. Ebitani, React. Kinet., Mech. Catal., 2012, 106, 185-192. 